\title{
ASPEK PENGETAHUAN, SIKAP DAN KETERAMPILAN PADA RESPON PETANI TERHADAP UPJA DI KECAMATAN TOHO
}

\author{
Ellyta $^{* 1}$, Mulyati ${ }^{1}$, Hery Medianto Kurniawan ${ }^{1}$, Ekawati ${ }^{1}$ \\ ${ }^{1}$ Program Studi Agribisnis, Fakultas Pertanian Universitas Panca Bhakti \\ *e-mail: ekawatiupb@gmail.com
}

\begin{abstract}
The use of agricultural tools and machinery has become a primary needs of farmers in processing and increasing their farming production, this activity encourages the emergence of agicultural tools and machinery service unit (UPJA) that has an intention in assistaining farmers in achieving time and energy efficiency and also in order to overcome scarcity of farmer resources in processing their farming. However, the delayed development of UPJA in several regions has encouraged this research in order to analyze farmers' responses to the use of agricultural tools and machinery service unit. Research method: This study was conducted at the Bukit Raya UPJA Village Pak Leheng Toho District from January - March 2018. This research used the descriptive analysis data, which was displayed in table form with several categories that have been determined based on aspects of knowledge, attitude and skills. Response measurements were carried out using a Likert scale (scoring) with a score of 1-5. The results of the all of the farmer showed that the response analysis from the aspects of knowledge, attitude and skills of UPJA Bukit Raya amounted to 3.48 in the good category, which means that farmers generally gave a good respond to the existence of the UPJA Bukit Raya Village, in Pak Leheng Village, Toho District.
\end{abstract}

Keywords: Agricultural Machinery, Farmer Energy Efficiency, Likert Scale

\section{PENDAHULUAN}

Sektor pertanian masih merupakan sektor yang penting dalam perekonomian Kalimantan Barat. Hal ini terlihat dari indikator ekonomi seperti pendapatan Domestik Regioanal Bruto. Dalam sepuluh tahun terakhir ini, kontribusi rata-rata mencapai $25 \%$ dari total PDRB riil. Hasil penelitian Rizieq (2017) menyebutkan bahwa pertumbuhan di sektor pertanian akan mendorong pertumbuhan Perekonomian di Kalimantan Barat dan tidak sebaliknya. Oleh karenanya pertumbuhan sektor pertanian menjadi sangat penting. Salah satu cara untuk meningkatkan pertumbuhan di sektor pertanian adalah dengan peningkatan produksi pertanian.

Peningkatan produksi pertanian yang optimal dapat diperoleh melalui pemanfaatan sumber daya alam dan sumber daya manusia yang tersedia secara efisien, efektif dan selektif. Peningkatan produksi pertanian, khususnya dalam prapanen sampai pascapanen memerlukan dukungan berbagai sarana dan prasarana produksi salah satu yang terpenting adalah dukungan alat mesin pertanian (Alsintan).

Penggunaan alsintan saat ini sudah menjadi kebutuhan pokok petani dalam mengelola usahataninya seperti mengolah tanah, tanam, panen dan pasca panen, dengan semakin kurangnya ketersediaan tenaga kerja karena telah banyak yang beralih profesi ke non pertanian (Subagiyo, 2016). Penggunaan alat dan mesin pertanian dalam proses produksi mendorong 
munculnya usaha-usaha ekonomi dalam pelayanan jasa alat dan mesin pertanian dalam bentuk kelembagaan unit pelayanan jasa alsinta (UPJA). Menurut Seno dkk (2018), bahwa usaha penggilingan padi memberikan keuntungan dan layak dikembangkan dengan memanfaatkan teknologi baru, manejemen dan kelembagaannya. Melalui penyediaan jasa alsintan diharapkan dapat mengefisienkan waktu dan tenaga dan untuk mengatasi masalah kelangkaan sumber daya petani dan usaha tani pada kondisi dimana kepemilikan alsintan secara individu tidak menguntungkan. Menurut Yeni dan Dewi (2014), bahwa UPJA memberikan dampak pada peningkatan kesempatan kerja dan berusaha, efisiensi dalam pengolahan tanah, penanganan pasca panen dan percepatan alih teknologi. Kinerja alsintan memberikan jaminan keamanan dalam proses produksi dengan memperhitungkan skala ekonomi yang melekat pada masingmasing jenis alsintan (Sugiarto, 2010), mampu menekan biaya usaha tani dan memberikan keuntungan bagi petani (Raharjo dan Herwenita, 2018).

Pemerintah melalui Dinas Pertanian Kabupaten Mempawah telah menyalurkan bantuan alat dan mesin pertanian dalam rangka meningkatkan produksi khususnya tanaman pangan. Berdasarkan data BPS Kalbar, sampai tahun 2017 terdapat 364 mesin pengolahan lahan (traktor), 23 buah mesin untuk penanaman, 6036 buah alat untuk pembasmian hama penyakit, 71 buah alat dan mesin untuk pengairan/pompa air dan 10 buah mesin combine harvester. Salah satu UPJA yang mendapatkan bantuan alsintan adalah UPJA Bukit Raya desa Pak Leheng Kecamatan Toho.

Kecamatan Toho merupakan salah satu sentral produksi pangan di Kabupaten Mempawah. Daerah yang cukup potensial untuk pengembangan lahan usaha tani terutama padi sawah. Sistem usaha tani dari sisi penggunaan teknologi terutama penggunaan alat dan mesin pertanian (alsintan) dari tahun ke tahun mengalami perkembangan. Semula petani belum ada yang menggunakan mesin pertanian, tapi sekarang sebagian petani sudah menggunakan mesin pertanian untuk mengantikan kelangkaan sumberdaya petani terutama dalam hal pengolahan tanah. Produksi padi selama beberapa periode tanam mulai meningkat. Namun peningkatannya tidak terlalu signifikan seperti yang diharapkan. Berdasarkan pengamatan dan wawancara dengan petani dan petugas penyuluh lapangan, produktivitas padi rata-rata $2.5-3$ ton/ha masih rendah dibandingkan rata-rata produktivitas padi nasional 5.5 ton/ha. Disamping itu, masih banyak petani yang belum memanfaatan jasa alat dan mesin pertanian yang dikelola UPJA Bukit Raya dalam proses produksi. Misalnya dalam pengolahan lahan, masih banyak petani masih menggunakan cara tanpa olah tanah (TOT) dibandingkan menggunakan traktor, dalam proses panen dan pasca panen petani masih menggunakan alat-alat yang sederhana sehingga persentase kehilangan masih cukup tinggi dan produksi yang dihasilkan tidak mengalami peningkatan yang signifikan. Menurut Hartadi (2016) bahwa kinerja UPJA kurang memuaskan dikarenakan jumlah alat yang masih sedikit. Ekawati dkk (2018) menyatakan bahwa teknologi dan Infrastruktur dalam mendukung keberlanjutan ketersediaan beras di Kalimantan Barat menghasilkan nilai indeks sebesar $42.52 \%$, berada pada katagori kurang berlanjut, menunjukkan kondisi teknologi dan infrastruktur saat ini kurang mendukung untuk ketersediaan beras berkelanjutan. Disamping itu juga diperlukannya pemetaan berkenaan dengan kebutuhan dan ketersediaan alsintan serta upaya kelembagaan untuk peningkatan efektifitasnya (Aidillah, 2016).

UPJA dibangun untuk memberikan manfaat positif yang seharusnya menguntungkan petani. Pembangunan ekonomi pertanian yang diharapkan dari pengadaan program tersebut 
belum sepenuhnya mampu meningkatkan kualitas serta kesejahteraan hidup petani. Hal ini dapat disebabkan oleh karena kurangnya respon petani terhadap program-program yang telah diluncurkan oleh pemerintah tersebut.

Berdasarkan hal tersebut maka perlu dilakukan pengkajian sejauh mana respon petani terhadap penggunaan jasa alat dan mesin pertanian yang dikelola oleh kelompok UPJA Bukit Raya Kecamatan Toho.

\section{METODE PENELITIAN}

Lokasi penelitian ditentukan secara sengaja (purposive) yaitu pada kelompok UPJA Bukit Raya Desa Pak Leheng Kecamatan Toho Kabupaten Mempawah, dengan pertimbangan merupakan salah satu desa yang telah diterapkan program perberdayaan UPJA dalam pelayanan jasa alat dan mesin pertanian (Alsintan) yang perkembangan kelompok UPJA lambat (kurang aktif). Penelitian ini dilaksanakan pada bulan Januari - Maret 2018.

Data primer diperoleh melalui jawaban kuesioner terstruktur dari responden petani padi yang berjumlah 26 orang petani yang berkaitan bagaimana respon petani terhadap UPJA Bukit Raya dalam pelayanan jasa Alsintan. Aspek yang diteliti mencakup aspek pengetahuan petani terhadap program UPJA, aspek sikap dan aspek keterampilan. Data sekunder diperoleh dari data dan informasi tertulis yang ada di lapangan dan dari instansi terkait.

Analisis data dilakukan secara deskriptif, dimana data ditampilkan dalam bentuk tabel dengan kategori yang telah ditentukan. Pengukuran respon dilakukan dengan menggunakan skala likert (skoring) dengan skor 1-5 yang meliputi 5 katagori yaitu sangat setuju (SS), setuju (S), netral (N), tidak setuju (TS) dan sangat tidak setuju (STS).

Tahapan analisis data berdarakan Umar (2010), untuk menginterpretasikan nilai yang diperoleh pada kriteria respon, rentang skor (range) dihitung dengan langkah - langkah sebagai berikut :

1. Menetukan total skot tertinggi yaitu: skor tertinggi $\mathrm{x}$ jumlah responden

2. Menentukan skor terendah yaitu: skor tererndah $\mathrm{x}$ jumlah responden

3. Menentukan total range yaitu: total Range $=\frac{\text { Total skor tertinggi-Total skor terendah }}{\text { Skor tertinggi }}$

4. Menentukan rata-rata range yaitu: rata - rata range $=\frac{\text { Total Range }}{\text { Jumlah Responden }}$

Dalam penelitian ini diperoleh kriteria respon dari responden dengan range sebesar 0,8 seperti dijelaskan pada Tabel 1.

Tabel 1. Kriteria Respon Petani terhadap UPJA Bukit Raya

\begin{tabular}{|c|c|}
\hline Rata - Rata Nilai & Kriteria Respon \\
\hline$>4,2-5,0$ & Sangat Baik \\
\hline$>3,4-4,2$ & Baik \\
\hline$>2,6-3,4$ & Cukup Baik \\
\hline$>1,8-2,6$ & Rendah \\
\hline $1,0-1,8$ & Sangat Rendah \\
\hline
\end{tabular}

Sumber: Data Primer diolah, 2018 


\section{HASIL DAN PEMBAHASAN}

Respon adalah suatu reaksi yang timbul dari pengamatan terhadap obyek tertentu (Wirawan, 2005). Kriteria respon dari 26 responden petani terhadap unit pelayanan alsintan UPJA Bukit Raya dapat diketahui melalui hasil rata - rata nilai analisis respon terhadap masingmasing variabel ditinjau dari aspek pengetahuan, aspek sikap dan aspek keterampilan.

\section{Aspek Pengetahuan}

Aspek Pengetahuan petani yang diukur meliputi pengetahuan pembelajaran program UPJA, pengetahuan tentang peningkatan produktivitas melalui program UPJA, dan wawasan petani mengenai program UPJA. Berdasarkan hasil penelitian diperoleh nilai rata-rata aspek pengetahuan petani seperti disajikan pada Tabel 2.

Berdasarkan Tabel 2 menunjukkan bahwa nilai rata - rata aspek pengetahuan petani terhadap UPJA Bukit Raya adalah 3,50 yang berada dalam kriteria baik. Hal ini berarti bahwa tingkat pengetahuan petani terhadap unit pelayanan jasa alsintan (UPJA) Bukit Raya termasuk dalam kriteria baik.

Pengetahuan yang tinggi memiliki pengaruh terhadap produktivitas. Sumber dan penyebaran berbgai informasi mengenai program UPJA sudah cukup baik yang secara langsung menambah pengetahuan petani dalam berusaha tani untuk meningkatkan produktivitas. Semakin tinggi tingkat pengetahuan petani maka kemampuannya dalam mengadopsi teknologi di bidang pertanian juga tinggi, demikian juga sebaliknya. Hal senada juga dikemukan oleh Fadhilah dkk (2017) yang menyatakan bahwa adanya pengetahuan yang baik tentang suatu hal, akan mendorong terjadinya perubahan prilaku pada diri individu. Pengetahuan tentang manfaat suatu hal akan menyebabkan seseorang berprilaku positif terhadap hal tersebut demikian pula sebaliknya. Informasi petani terkait UPJA banyak diperoleh petani dari kegiatan non formal seperti penyuluhan dan pelatihan (Husnayati dkk, 2018)

Tabel 2. Nilai Rata-Rata Aspek Pengetahuan Petani Terhadap UPJA Bukit Raya Desa Pak Laheng Kecamatan Toho

\begin{tabular}{|c|c|c|c|}
\hline No & Pertanyaan & $\begin{array}{c}\text { Nilai } \\
\text { Rata-Rata }\end{array}$ & Kriteria \\
\hline \multicolumn{4}{|c|}{ Pengetahuan pembelajaran program UPJA } \\
\hline 1. & Mengetahui apa itu program UPJA & 3,92 & Baik \\
\hline 2. & Program UPJA merupakan pengetahuan baru bagi petani & 3,88 & Baik \\
\hline & $\begin{array}{l}\text { Program UPJA yang dipakai sudah disesuaikan dengan } \\
\text { kondisi fisik, sosial dan ekonomi disini }\end{array}$ & 3,42 & Baik \\
\hline & $\begin{array}{l}\text { Program UPJA lebih efektif dibandingkan penyewaan jasa } \\
\text { alsintan lainnya }\end{array}$ & 3,73 & Baik \\
\hline \multicolumn{4}{|c|}{$\begin{array}{l}\text { Pengetahuan tentang peningkatan produktivitas melalui } \\
\text { program UPJA }\end{array}$} \\
\hline & $\begin{array}{l}\text { Program UPJA mampu meningkatkan hasil panen dan } \\
\text { kesejahteraan petani }\end{array}$ & 4,04 & Baik \\
\hline & Mengetahui dengan baik seluk beluk program UPJA & 3,19 & Cukup Baik \\
\hline
\end{tabular}


8. Mengetahui kondisi yang diperlukan untuk meningkatkan hasil panen dengan program UPJA

Wawasan mengenai program UPJA

9. Mengetahui keunggulan dan kelemahan program UPJA dibandingkan dengan penyewaan jasa alsintan lainnya

3,35 Baik

10. Mengetahui hasil penerapan program UPJA di daerah lain

2,65 Cukup Baik Rata - Rata Total Nilai Aspek Pengetahuan $\mathbf{3 , 5 0}$ Baik

Sumber: Data Primer diolah, 2018

Berdasarkan Tabel 2 diatas, bahawa nilai rata - rata aspek pengetahuan petani terhadap UPJA Bukit Raya adalah 3,50 yang berada dalam kriteria baik. Hal ini berarti bahwa tingkat pengetahuan petani terhadap unit pelayanan jasa alsintan (UPJA) Bukit Raya termasuk dalam kriteria baik.

Pengetahuan yang tinggi memiliki pengaruh terhadap produktivitas. Sumber dan penyebaran berbgai informasi mengenai program UPJA sudah cukup baik yang secara langsung menambah pengetahuan petani dalam berusaha tani untuk meningkatkan produktivitas. Semakin tinggi tingkat pengetahuan petani maka kemampuannya dalam mengadopsi teknologi di bidang pertanian juga tinggi, demikian juga sebaliknya. Hal senada juga dikemukan oleh Fadhilah dkk (2017) yang menyatakan bahwa adanya pengetahuan yang baik tentang suatu hal, akan mendorong terjadinya perubahan prilaku pada diri individu. Pengetahuan tentang manfaat suatu hal akan menyebabkan seseorang berprilaku positif terhadap hal tersebut demikian pula sebaliknya. Informasi petani terkait UPJA banyak diperoleh petani dari kegiatan non formal seperti penyuluhan dan pelatihan (Husnayati dkk, 2018)

\section{Aspek Sikap}

Aspek sikap petani yang diukur dari sikap petani terhadap program UPJA, sikap petani terhadap penerapan program UPJA, dan peran aktif petani terhadap program UPJA. Hasil analisis data secara rinci diihat pada Tabel 3.

Tabel 3. Nilai Rata-Rata Aspek Sikap Petani Terhadap UPJA Bukit Raya Desa Pak Laheng Kecamatan Toho

\begin{tabular}{ccc}
\hline \multicolumn{1}{c}{ Pertanyaan } & $\begin{array}{c}\text { Nilai } \\
\text { Rata-Rata }\end{array}$ & Kriteria \\
\hline $\begin{array}{c}\text { Sikap petani terhadap program UPJA } \\
\text { 1. } \quad \text { Mampu memberikan masukan terhadap program UPJA }\end{array}$ & 3,73 & Baik \\
2. Menerapkan program UPJA karena anjuran Dinas & 2,96 & Cukup Baik \\
3. $\quad \begin{array}{l}\text { Dapat membandingkan jasa penyewaan alsintan lainnya } \\
\text { dengan program UPJA }\end{array}$ & 3,19 & Cukup Baik \\
4. Menggunakan jasa penyewaan alsintan selain UPJA & 2,96 & Cukup Baik \\
5. Menerapkan program UPJA karena mengikuti petani & 2,31 & Rendah \\
$\quad$ tetangga di desanya & & \\
Sikap petani terhadap penerapan program UPJA & 4,12 & Baik \\
6. Percaya program UPJA dapat meningkatkan hasil panen & 3,42 & Baik \\
7. Mampu menilai untung - rugi menerapkan program UPJA & Baik \\
8. Menerima konsekuensi menerapkan program UPJA sebagai & 3,46 & \\
$\quad \quad$ pembelajaran dalam berusaha tani & &
\end{tabular}


9. Mampu memberikan saran kepada penyuluh untuk perbaikan program UPJA

10. Mampu memberikan pengalamannya kepada penyuluh dan petani lain tentang program UPJA

3,81 Baik

11. Bersedia dikoordinasikan dengan para petani kelompoknya dalam menerapkan program UPJA

Baik

Sumber: Data Primer diolah, 2018

\section{Rata - Rata Total Nilai Aspek Sikap}

Berdasarkan Tabel 3, nilai rata - rata aspek sikap petani terhadap UPJA Bukit Raya adalah 3,48 dan termasuk dalam katagori baik, yang menunjukkan bahwa sikap petani terhadap keberadaan UPJA Bukit Raya adalah baik, petani mendukung keberadaan UPJA Bukit Raya.

Aspek sikap petani mendukung program UPJA bukan hanya karena anjuran dari pemerintah, namun petani dapat melihat perbandingan hasil yang diperoleh dengan menggunakan program UPJA. Hasil panen padi yang diperoleh dengan menggunakan program UPJA lebih besar, sehingga dengan sendirinya dapat menilai untung rugi dari penerapan program UPJA. Hal ini karena dengan program UPJA dapat lebih mengefisienkan waktu, tenaga dan biaya yang harus dikeluarkan petani. Petani dapat memberikan masukan terhadap program UPJA untuk lebih meningkatkan hasil produktivitas serta berkoordinasi dengan petani lain dalam rangka penerapan program UPJA. Sikap petani yang tinggi terhadap suatu program pemerintah yang berarti bahwa petani terbuka untuk setiap informasi, inovasi, programprogram dan anjuran pemerintah dalam kegiatan usaha taninya (Fadhilah dkk, 2017). Percepatan adopsi inovasi juga dipengaruhi oleh keterhubungan dan keterbukaan petani dalam jaringan komunikasi baik di dalam maupun diluar kelompok tani (Ellyta dkk, 2019).

\section{Aspek Keterampilan}

Aspek keterampilan petani diukur dari ketarampilan dalam penerapan program UPJA, keterampilan dalam meningkatkan produktivitas melalui program UPJA dan keterampilan dalam memecahkan masalah dalam penerapan program UPJA. Hasil analisis data secara rinci diihat pada Tabel 4.

Tabel 4. Nilai Rata-Rata Aspek Keterampilan Petani Terhadap UPJA Bukit Raya Desa Pak Laheng Kecamatan Toho

\begin{tabular}{|c|c|c|c|}
\hline No & Pertanyaan & $\begin{array}{c}\text { Nilai } \\
\text { Rata - Rata }\end{array}$ & Kriteria \\
\hline & Keterampilan dalam penerapan program UPJA & & \\
\hline 1. & $\begin{array}{l}\text { Mampu menggunakan alsintan untuk peningkatan hasil } \\
\text { panen padi }\end{array}$ & 3,81 & Baik \\
\hline 2. & $\begin{array}{l}\text { Memerlukan pelatihan untuk dapat menggunakan } \\
\text { alsintan }\end{array}$ & 4,54 & Sangat Baik \\
\hline 3. & $\begin{array}{l}\text { Mampu menyesuaikan program UPJA dengan kondisi } \\
\text { fisik dan sosial di daerah }\end{array}$ & 3,46 & Baik \\
\hline 4. & $\begin{array}{l}\text { Memerlukan pendamping / menyuruh orang lain dalam } \\
\text { menggunakan alsintan }\end{array}$ & 4,15 & Baik \\
\hline 5. & Mengerti perbengkelan alat dan mesin pertanian & 3,12 & Cukup Baik \\
\hline 6. & $\begin{array}{l}\text { Memperhitungkan dampak menerapkan program UPJA } \\
\text { Keterampilan dalam peningkatan produktivitas } \\
\text { melalui program UPJA }\end{array}$ & 3,27 & Cukup Baik \\
\hline
\end{tabular}


7. Sebagian petani masih merasa lebih nyaman menggunakan jasa penyewaan alsintan lainnya dibanding menggunakan jasa UPJA untuk meningkatkan hasil panen padi

8. Jasa penyewaan alsintan lainnya mampu memberikan hasil panen yang sama dengan UPJA atau bahkan lebih baik

9. Mampu meningkatkan hasil panen padinya dengan program UPJA

10. Menguasai teknis penerapan program UPJA

\section{Keterampilan memecahkan masalah dalam} penerapan program UPJA

11. Mampu cepat belajar memecahkan masalah dalam menerapkan program UPJA

3,04 Cukup Baik

4,12 Sangat Baik

3,23 Cukup Baik

3,35

Baik

12. Mampu melakukan perbengkelan apabila terjadi kerusakan alat dan mesin pertanian

3,00 Cukup Baik

4,15 Baik

13. Memerlukan pendampingan penyuluh dalam menyelesaikan masalah dalam penerapan program UPJA

\begin{tabular}{rrrr}
\hline Rata - Rata Total Nilai Aspek Keterampilan & $\mathbf{3 , 5 2}$ & Baik
\end{tabular}

Sumber: Data Primer diolah, 2018

Berdasarkan Tabel 4 diatas, nilai rata - rata aspek keterampilan petani terhadap UPJA Bukit Raya adalah 3,52 dan termasuk dalam katagori baik. Hal ini menunjukkan bahwa sikap dari aspek keterampilan petani terhadap keberadaan UPJA Bukit Raya adalah baik, petani memiliki keterampilan yang baik dalam mengaplikasikan alsintan yang ada di UPJA Bukit Raya dalam usahataninya.

Keterampilan para petani sudah cukup baik didukung oleh keterampilan petani dalam kegiatan menerapkan program UPJA melalui pelatihan dan pendampingan untuk memecahkan masalah sehingga dapat meningkatkan produktivitas. Hal ini sejalan dengan pernyataan Nuryanti (2003) bahwa, keterampilan merupakan kecakapan atau kemampuan untuk menerapkan suatu inovasi bagaimana petani dapat mengulang segala sesuatu yang dilihatnya melalui kegiatan belajar dengan meniru gerakan, menggunakan konsep untuk melakukan gerakan dengan benar dan melakukan beberapa gerakan dengan benar dan wajar. Petani yang memiliki keterampilan yang tinggi akan diikuti dengan produksi yang dihasilkan juga tinggi (Wahyudi, 2017). Keterampilan petani ialah sebagai proses komunikasi untuk mengubah perilaku petani menjadi cekatan, cepat dan tepat melalui pengembangan teknologi. Keterampilan ini dibutuhkan dalam pengembangan pertanian dalam hal budidaya, dari pengolahan lahan hingga panen dan pasca panen melalui penggunaan alat - alat pertanian demi mendapatkan hasil produksi yang lebih maksimal. Untuk mendapatkan hasil maksimal dan produksi tinggi tentu di perlukan keterampilan petani yang dapat menunjang bagaimana aplikasi pertanian yang sebenar-benarnya, tentunya dari proses tanam sampai panen.

Berdasarkan aspek pengetahuan, aspek sikap dan aspek keterampilan, secara keseluruhan respon petani terhadap UPJA Bukit Raya Desa Pak Leheng dapat dilihat pada Tabel 5. 
Tabel 5. Rakapitulasi Nilai Rata-Rata Aspek Pengetahuna, Sikap dan Keterampilan Petani terhadap UPJA Bukit Raya Desa Pak leheng Kecamatan Toho

\begin{tabular}{llcc}
\hline No & \multicolumn{1}{c}{ Pertanyaan } & $\begin{array}{c}\text { Nilai } \\
\text { Rata - Rata }\end{array}$ & Kriteria \\
\hline 1. & Aspek Pengetahuan & 3,50 & Baik \\
2. & Aspek Sikap & 3.41 & Baik \\
3. & Aspek Keterampilan & 3,52 & Baik \\
& Jumlah Rata-Rata Total & 10,43 & \\
\hline & Nilai Rata-Rata Akhir & 3,48 & Baik \\
\hline
\end{tabular}

Sumber: Data Primer diolah, 2018

Berdasarkan Tabel 5, bahwa nilai rata - rata akhir dari 3 aspek yang diteliti yaitu aspek pengetahuan, aspek sikap dan aspek keterampilan yaitu sebesar 3,48 berada dalam kriteria baik. Hal ini sejalan dengan hasil wawancara dan implementasi di lapangan, bahwa dari 26 orang petani sampel, sebanyak 18 orang $(69,23 \%)$ telah konsisten dan secara terus - menerus berpastisipasi dalam menggunakan program UPJA dengan rentang 4-7 kali partisipasi, sedangkan 8 orang petani sampel $(30,77 \%)$ belum secara konsisten berpastisipasi dalam menggunakan program UPJA yaitu dengan rentang partisipasi 1-3 kali, hal ini dikarenakan masih ada keraguan karena belum sepenuhnya memahami kelebihan dan keuntungan dalam menerapkan program UPJA, sehingga diperlukan penyuluhan dan pembinaan secara berkelanjutan.

Upaya pengembangan program UPJA untuk meningkatkan produktivitas padi bagi petani di desa Pak Laheng Kecamatan Toho perlu terus dilakukan melalui penyebarluasan program UPJA yang lebih intensif. Penambahan pengetahuan lebih kearah pengetahuan praktis yaitu ilmu yang diberikan langsung ditujukan kepada pemakaian atau pengalaman sehingga menentukan bagaimana seseorang harus berbuat sesuatu. Pengetahuan petani bertambah setelah memahami dan menerapkan program UPJA dalam pelaksanaan pengembangan usaha taninya sehingga produktivitas padi meningkat. Hal ini sesuai dengan pendapat Maintang (2012) bahwa, pengetahuan tentang adanya suatu teknologi sangat penting, karena dengan petani mengetahuinya akan timbul kemauan untuk menerapkannya. Hal ini terkait erat dengan peranan peneliti, penyuluh, dan dinas terkait mulai dari sosialisasi teknologi hingga pendampingan teknologi di lapangan.

Penyuluhan dan pendampingan dalam penyebaran teknologi perlu dibangun secara lebih baik melalui metode partisipatif dengan melibatkan petani dari tahap perencanaan, pelaksanaan, evaluasi kegiatan sehingga petani dapat memperoleh pembelajaran dalam upaya meningkatkan produktivitas.

Keberhasilan program UPJA akan sulit berkembang dengan sendirinya tanpa dipicu, dibantu atau dikawal. Untuk mempercepat dan mempertajam keberhasilan program UPJA diperlukan bantuan pendampingan. Pendampingan program UPJA oleh penyuluh lapangan yang berperan sebagai 1) pemandu yang paham terhadap permasalahan, kebutuhan dan kekuatan yang ada di desa, 2) Pelatihan program UPJA sehingga menimbulkan ketertarikan dan lebih menghidupkan keinginan untuk ikut berpartisipasi didalamnya, 3) motivator yang kaya akan pengalaman dalam berolah tanam dan dapat membantu membangkitkan kepercayaan diri 
para petani, 4) konsultasi bagi petani untuk mempermudah menentukan langkah - langkah selanjutnya dalam berusahatani.

\section{KESIMPULAN DAN SARAN}

\section{Kesimpulan}

Berdasarkan hasil analisis respon petani secara keseluruhan dari aspek pengetahuan, aspek sikap dan aspek keterampilan terhadap UPJA Bukit Raya sebesar 3,48 yang berada dalam katagori baik, yang artinya bahwa secara umum petani merespon baik terhadap keberadaan UPJA Bukit Raya Desa Pak Leheng Kecamatan Toho. Begitu juga jika dilihat setiap aspek juga dalam kriteria baik. Aspek pengetahuan nilai rata-rata 3,50 kriteria baik, aspek sikap nilai ratarata 3,41 termasuk dalam kriteria baik dan aspek keterampilan dengan nilai 3,52 dalam kriteria baik.

\section{Saran}

Berdasarkan hasil analisis data baik dari aspek pengetahuan, aspek sikap dan aspek keterampilan ada beberapa sub aspek yang perlu mendapat perhatian untuk ditingkatkan dan dikembang diantaranya: Aspek pengetahuan dan sikap, yang memiliki nilai terendah yaitu mengetahui hasil penerapan program UPJA di daerah lain dan menerapkan program UPJA karena mengikuti petani tetangga di desanya. Hal ini perlu mendapat perhatian, petani harus mendapat informasi tentang keberhasilan petani daerah lain dalam penerapan alsintan misalkan produksi yang dihasilkan, hal ini akan menjadi motivasi petani untuk menerapkan alsintan pada usahataninya

\section{DAFTAR PUSTAKA}

Aldillah, R. 2016. Kinerja Pemanfaatan Mekanisasi Pertanian dan Implikasinya dalam Upaya Percepatan Produksi Pangan di Indonesia. Forum Penelitian Agroekonomi. 34 (2). 163 177.

Ekawati, Kusnandar., Kusrini, N., \& Darsono. (2018). Impact of Technology and Infrastucture Support fos Sustainable Rice in West Kalimantan, Indonesia. Bulgarian Journal of Agricultural Science, 24 (06), 942-948.

Ellyta. Mustakim. U.Z. dan Rizieq, R. 2019. Pengembangan Adopsi Inovasi Melalui Jaringan Komunikasi. Jurnal Ziraa'ah. 44 (1). 83-90.

Fadhilah, M. L., Eddy, B. T., \& Gayatri, S. (2017). Pengaruh Tingkat Pengetahuan, Sikap dan Keterampilan Penerapan Sistem Agribisnis Terhadap Produksi Pada Petani Padi di Kecamatan Cimanggu Kabupaten Cilacap. Jurnal Agrisocionomics. 2(1). 39-49.

Hartadi, M.A. 2016. Analisis Kinerja Usaha Pelayanan Jasa Alat dan Mesin Pertanian (UPJA) di Kabupaten Nunukan. Tugas Akhir Program Megister. Program Pasca Sarjana Universitas Terbuka. Jakarta. 
Husnayati, L.G. Suwarto. dan Ihsaniyat, H. 2018. Persepsi Petani terhadap UPJA di Kecamatan Tawangsari Kabupaten Sukoharjo. https://jurnal.uns.ac.id/agritexts/article/view/34046

Maintang. (2012). Pengelolaan Tanaman Terpadu dan Teknologi Pilihan Petani: Kasus Sulawesi Selatan. Jurnal IPTEK Tanaman Pangan, 7 (2)

Nuryati, L.D. (2003). Peranan Media Komunikasi terhadap Prilaku Petani dalam Berusaha Tani Melon (Curcumis Melo L) di Kabupaten Medium. Malang. Fakultas Pertanian Universitas Brawijaya.

Raharjo, B dan Herwenita. 2018. Efektivitas Pelatih Budidaya Padi Berbasis Mekanisasi terhadap Peningkatan Pengetahuan serta Sikap dan Respon Petani di Kabupaten Banyuasin Sumatera Selatan. Proseding Seminar Nasional Perteta 29-31 Agustus 2010. Institut Pertanian STIPER. Yogyakarta. 118-128.

Rizieq, R. 2017. Analisis Kausalitas Sektor Pertanian dalam Pendapatn Domestik Bruto Riil Kalimantan Barat. Jurnal Agrosains, 13 (2), 30-35

Seno, F.W. Rizieq. R dan Ellyta. 2018. Analisis Finansial Usaha Penggilingan Beras Maju Bersama di Dusun Sebadak. Jurnal Equilibrium. 4 (2). 1-7.

Subagiyo. (2016). Analisis Kelayakan Finasial Penggunaan Alsintan dalam Usaha Tani Padi di Daerah Istimewa Yogyakarta. Jurnal AGROS, 18 (1), 33-48

Sugiarto. 2010. Analisis Kinerja UPJA Menunjang Kegiatan Usaha Tani Padi. Jurnal Penelitian Pertanian Terapan. 10 (2). 118-130.

Umar, H. (2010). Metode Penelitian untuk Skripsi dan Tesis Bisnis. Jakarta. PT Rajagrafindo Persada.

Wahyudi, R.F. Jamaluddin dan Rendra. 2017. Hubungan Prilaku Petani terhadap Pelaksanaan Usahatani Padi Sawah Lebak dengan Produktivitas di Kecamatan Sekernan Kabupaten Mauro Jambi. http://respository.unja.ac.id/3272/1/jurnal\%20rici\%20fw.pdf. Diakses 26 Oktober 2019.

Wirawan, S.S. (2005). Psikologi Lingkungan. Jakarta. PT Gramedia Grasindo.

Yani, F dan Dewi, N. 2014. Analisis Sistem Unit Pelayanan Jasa Alsintan (UPJA) DI Kecamatan Kuala Kampar Kabupaten PELAlawan. Jurnal Dinamika Pertanian. XXIX (2). $169-182$ 